\title{
Análisis cronológico de la postmodernidad en el periodismo literario de opinión del diario El País
}

\author{
David NAVARro MartínEZ \\ Universidad Europea Miguel de Cervantes \\ david.navarro.esc@gmail.com
}

\section{Resumen:}

El análisis histórico se presenta como una alternativa para estudiar el periodismo literario, estableciendo relaciones objetivas entre este tipo de periodismo y los rasgos que definen cada una de las etapas literarias. Desde este punto de vista, es posible encontrar rasgos de la literatura postmoderna en el periodismo literario de opinión a través de las décadas en las que se desarrolla la postmodernidad en España. El diario El País surge en una fecha muy próxima a la llegada de esta nueva corriente de pensamiento a nuestro país, por lo que puede servirnos para acometer este análisis.

Palabras clave: Periodismo literario; postmodernidad; El País

\section{Chronological analysis of postmodernism in literary opinion journalism in the newspaper El País}

\begin{abstract}
:
Historical analysis is regarded as an alternative to study literary journalism, setting objective relations between this kind of journalism and all the features that define each literary period. From this point of view, it is posible to find features of postmodern literature in the literary opinión journalism throughout the decades that postmodernism was developing in Spain. The newspaper El País emerged right before this new school of thought arrived to our country, therefore this publicación can help us engage the analysis.
\end{abstract}

Key Words: Literary jorunalism; postmodernism; El País

\section{Referencia normalizada:}

Navarro Martínez, D. (2014): Análisis cronológico de la postmodernidad en el periodismo literario de opinión del diario El País. Historia y Comunicación Social. Vol. 19. Núm. Especial Marzo. Págs. 83-91.

Sumario: 1. Introducción y estado de la cuestión. 2. Metodología empleada. 2.1. Selección de la muestra. 2.2. Descripción de la plantilla de análisis. 3. Rasgos de la postmodernidad en el periodismo literario de opinión en el diario El País (1976-2006). 3.1. Años 70. 3.2. Años 80. 3.3. Años 90. 3.4. Años 2000. 4. Conclusiones. 5. Referencias bibliográficas. 


\section{Introducción y estado de la cuestión}

El estudio del periodismo literario es relativamente reciente, pero son muchos los teóricos de la comunicación y la literatura, tanto españoles como extranjeros, los que han reflexionado al respecto. Al existir pocos estudios aún sobre este tipo de periodismo, las bases sobre las que se argumenta su existencia aún no son suficientemente sólidas. Muchos autores afirman que los recursos literarios pueden dificultar la comprensión de los textos y pueden dañar su objetividad cuando son utilizados en los géneros informativos, principalmente, mientras otros sostienen que el periodismo debe enriquecerse en todos los géneros mediante la utilización de estos recursos. Uno de los problemas de esta segunda opción estriba en la definición de lo estético, es decir, en la búsqueda de un procedimiento universal para catalogar lo que es periodismo literario y lo que no lo es atendiendo a características formales. Los autores que defienden la existencia y conveniencia de este tipo de periodismo presuponen que el público receptor en su conjunto puede diferenciar intuitivamente entre un texto literario y uno no literario.

Debemos avanzar precisamente en esta línea de estudio para ofrecer una respuesta a la pregunta ¿Qué es el periodismo literario?, así como para proponer claves que puedan aplicarse en su identificación. Una definición de la estética literaria pasa necesariamente por una mirada muy minuciosa a la historia. Repasando individualmente cada contexto artístico se pueden encontrar particularidades que hacen del hecho literario lo que es: un proceso de comunicación de este mismo arte que rodea a cada sociedad en cada momento.

En este punto hay que tener en cuenta que el periodismo, por su propia definición, nunca se ha desvinculado de la realidad sobre la que habla. Siempre ha estado más o menos relacionado con los momentos culturales e ideológicos, y siempre ha marcado las preocupaciones de su audiencia, tal y como sostiene la teoría de la agenda-setting. En otras palabras, el periodismo no puede evitar ser un reflejo de la vida, tanto en forma como en contenido. Las relaciones históricas entre periodismo y literatura se pueden comparar de esta manera extrayendo los elementos estéticos, ideológicos y temáticos de cada período artístico y observando cómo tanto en literatura como en periodismo literario (de opinión, en el estudio que nos ocupa) dichos elementos coinciden.

Esta visión histórica nos abre una puerta para proponer una definición objetiva de periodismo literario, en cuanto que también se puede definir objetivamente cualquier movimiento artístico. Para identificar el periodismo literario en el momento actual, se hace preciso hablar sobre el universo social y cultural que nos rodea desde hace algunas décadas: la postmodernidad y el Postmodernismo cultural. Extrayendo las características de esta intrincada y confusa etapa de nuestra historia, podremos proceder a aplicar las conclusiones a nuestra investigación, y así acometer una misión que la Teoría del Periodismo todavía no ha cumplido: hallar los rasgos de la postmodernidad y el Postmodernismo cultural en el periodismo literario español actual y de los últimos años. 


\section{Metodología empleada}

\subsection{Selección de la muestra}

El objetivo de este análisis es la identificación de los rasgos de la postmodernidad y el Postmodernismo cultural en el periodismo literario de opinión español de las últimas décadas. Para ello se procedió a un análisis de contenido cualitativo de los artículos de opinión encontrados siguiendo el proceso de selección de la muestra detallado a continuación y mediante una plantilla de análisis que recoge los principales rasgos (estéticos, temáticos e ideológicos) del contexto cultural postmoderno.

La localización de los artículos de opinión analizados en esta investigación se centró en el periódico de tirada nacional El País. Se ha elegido este diario por ser actualmente el más leído según los diferentes estudios de audiencia, y también por haber nacido en 1976, un año que simboliza el pleno apogeo de la postmodernidad en España. Esta etapa cultural se desarrolla desde los años 70 del siglo XX, y los expertos distinguen diversas etapas identificadas por décadas. Por esta razón convenimos que el análisis deberá hacerse con una muestra procedente de las distintas décadas. Seleccionamos los periódicos de los años 1976, 1986, 1996 y 2006. El año 1976, además de ser el año de nacimiento de El País, es el primer año en que se otorga el premio Cervantes, que está considerado como el galardón más importante de la literatura en lengua castellana y que es uno de los premios que tendremos en cuenta a la hora de seleccionar los autores de los artículos de opinión analizados en esta investigación. Además, consideramos que en el año 1976 ya están suficientemente asentados la postmodernidad y el Postmodernismo cultural en España. En concreto, analizamos una semana de cada uno de estos años: la del 25 al 31 de mayo. Elegimos esta semana porque es informativamente típica, sin citas políticas o deportivas importantes, lo que suma representatividad a los resultados. En total, siete periódicos por semana, excepto en la década de los 70, en la que se analizaron seis periódicos debido a que los lunes no se ponía a la venta El País, sino que existía la llamada "Hoja del lunes", que hasta 1982 fue el único periódico que estaba autorizado a publicarse el primer día de cada semana.

Para la elección de los artículos de opinión escritos por literatos objeto de estudio, se configuró un listado de escritores ganadores del premio Cervantes, o ganadores o finalistas de los premios Nadal y Planeta. Consideramos que un estudio sobre el periodismo literario debe hacerse justamente sobre los textos de opinión escritos por estos literatos, cuya importancia en el panorama cultural español viene definida y justificada por los galardones que han recibido (y más teniendo en cuenta que la literatura postmoderna está íntimamente relacionada con los premios y el mercado de masas). En el proceso de muestreo se han encontrado 22 artículos. 


\subsection{Descripción de la plantilla de análisis}

En la primera parte de la plantilla se aportan unos datos generales del análisis: cuándo fue publicado el artículo y el número de artículos de opinión analizados ese día. Esta clasificación nos ayuda a averiguar si el periodismo literario está concentrado en unos días concretos de la semana o no.

Después de estos datos generales, se procede al análisis específico de cada artículo. Señalamos qué premios literarios ha ganado el autor del artículo, y también la fecha en que lo hizo. A partir de aquí puede deducirse si uno de los premios tiene preponderancia sobre los otros, y si los periódicos cuentan con los escritores en su plantilla a partir de los premios que han ganado y su reconocimiento asociado, o si por el contrario han sido visionarios y han apostado por su firma.

Una vez realizado este análisis inicial, se procede a abordar los elementos de la postmodernidad y el Postmodernismo cultural y literario encontrados en cada uno de los artículos. Para ello, se acude a la distinción entre elementos estéticos, temáticos e ideológicos que conforman todo período literario. En la plantilla utilizada se distinguen, en el caso de los elementos estéticos postmodernos, los generales y los específicos por décadas: 70, 80, 90 y 2000, detectados por los autores especializados. Lo mismo sucede en la detección en los artículos de opinión de los literatos en lo referente a las temáticas y las ideologías postmodernas.

En el caso de los elementos estéticos, distinguimos si el autor del artículo utiliza este elemento para la redacción del texto, o si simplemente alude a él. En este último caso, discernimos si el autor realiza un juicio de valor positivo o negativo hasta este elemento, o si opta por no posicionarse. En los elementos temáticos, destacamos la utilización del elemento si el artículo analizado gira claramente en torno a ese tema, o si únicamente hace una alusión a él. En este caso, también distinguimos entre juicio de valor positivo o negativo, o simple referencia al tema. En cuanto a los elementos ideológicos, señalamos si hay una ideología que recorre todo el artículo, en cuyo caso hablamos de utilización. En cualquier otro caso, procedemos tal y como ya se ha explicado en los anteriores elementos: indicamos si hay una alusión neutral, o un posicionamiento con un juicio de valor asociado, positivo o negativo.

Esta clasificación contribuye a concluir qué elementos de la postmodernidad tienen un mayor reflejo en el periodismo literario de opinión, y cómo se posicionan los autores ante el contexto estético, temático e ideológico actual. Es importante estudiar los tres tipos de elementos por separado, porque la literatura postmoderna es difícilmente disociable del contexto social en el que se enmarca. 


\section{Rasgos de la postmodernidad en el periodismo literario de opinión en el diario El País (1976-2006)}

\subsection{Años 70}

Durante la década de los 70, se han encontrado cinco artículos en El País que cumplen los requisitos para el análisis. Estos cinco artículos han sido escritos por cuatro autores: Jesús Fernández Santos, Fernando Savater, Jesús Jiménez Lozano y Ricardo de la Cierva. Los artículos se han localizado durante los días del miércoles, del viernes y del domingo, por lo que no existe una clara preponderancia de periodismo literario en ningún día o etapa concreta de la semana. La gran mayoría de premios que han recibido estos autores les fueron otorgados después del año 1976, por lo que existe por parte del periódico una apuesta firme y confiada hacia escritores españoles que en esa época aún no habían obtenido uno de los tres grandes premios literarios.

Los elementos estéticos de la postmodernidad encontrados van en la línea de la superación del experimentalismo y de la linealidad y simplicidad argumental propia de los años 80. En este sentido, el periodismo literario se adelanta a la literatura. También podemos encontrar rasgos típicos de la literatura de la década de los 70 , como es la vuelta hacia la narratividad, representada en la utilización del argumento como eje de la redacción, un elemento propio del subgénero de la crítica literaria o cinematográfica que participa de estos artículos. La actitud que se mantiene hacia los criterios estéticos postmodernos es de respeto, aunque tampoco se hace una valoración explícitamente positiva.

Los elementos temáticos que se han encontrado se adelantan en un porcentaje elevado a los que será la postmodernidad de los años 80 y 90 . No se dejan de lado ciertos "leitmotiv" como la importancia de lo subjetivo o la crisis de los sistemas de referencia. En este sentido, José Jiménez Lozano (1976: 15) en su artículo Problemas éticos de la explotación industrial del átomo por en relevancia la "preocupación de tipo socio-político que parecen mostrar las iglesias en contraste con las preocupaciones teológicas por las realidades vivas". Ya se adelantan temas como la reconstrucción histórica, los ambientes exóticos o la reflexión sobre los condicionamientos que limitan al individuo. Los artículos son muy variados y no se centran de forma global en ninguna de estas líneas. Lo que sí es representativo es que no existe por parte de los autores ningún juicio de valor sobre estos elementos, una decisión evidentemente relacionada con el tipo de artículos de los que se trata y los juicios a los que más recurren.

Ocurre lo mismo en el caso de los elementos ideológicos: El País se adelanta dos décadas para hablar sobre la importancia de asumir responsabilidades y de recuperar el pasado, lo que podría estar relacionado de alguna manera con su línea editorial progresista. También es reseñable que dos de los cinco artículos comulgan con la idea del ecologismo, tradicionalmente relacionado con el ala más progresista de la sociedad. En su análisis social riguroso y abierto, utiliza varias veces la idea de la 
coexistencia de principios contrarios sin acompañarla de un enjuiciamiento, de forma que expone las posibilidades de resolución de diferentes problemas desde diferentes perspectivas. Por ejemplo, Jesús Fernández Santos (1976: 21) en su artículo Hombre joven a la deriva habla de que se están "barriendo muchas ideas sobre ética y moral, hasta hace poco consideradas intocables".

\subsection{Años 80}

En los años 80 se han analizado seis artículos escritos por cuatro autores: Francisco Umbral, Manuel Vázquez Montalbán, Fernando Arrabal y Manuel Vicent. Es representativo que cuatro de estos artículos se encuentren en los periódicos de los dos primeros días de la semana: lunes y martes. En este caso no existe ningún patrón identificativo en la fecha de entrega de los diferentes premios a los autores citados, pero sí que se apunta una posible preferencia hacia los autores ganadores del premio Nadal, obtenido por tres de los autores.

El análisis sobre los elementos estéticos de la postmodernidad sigue basándose en el respeto y el no posicionamiento, además de en la superación del experimentalismo y la linealidad y simplicidad argumental.

En un década cultural e ideológicamente convulsa para España, los escritores toman nota de esta realidad tan compleja, y mediante la temática de los artículos ponen en evidencia la existencia de la confusión postmoderna entre lo real y lo virtual. De hecho, Francisco Umbral (1986: 60) asegura en el artículo La elipse que "la televisión nos ha habituado a elegir imágenes antes que ideologías". También se hace referencia a la modificación en la percepción del espacio y del tiempo, en relación de nuevo con la crisis de los sistemas de referencia.

Otra vez el periodismo postmoderno que encontramos engloba elementos de la mayoría de las décadas, aunque con un repunte de todo lo que significaron los años 80 en España. Sobre todo, en cuanto a ideología los autores exhortan a la reconstrucción histórica e incluyen referencias ambientales de nuestro país. Por ejemplo, Fernando Arrabal (1986: 13) habla sobre la época de la posguerra en su artículo Repugnantes petardistas, y clama: “ ¡Con qué nostalgia recuerdo a aquellos amigos de corazón junto a los que luché por la libertad de los presos políticos!". La opinión categórica se complementa con la descripción de la realidad identificable, un elemento tomado por adelantado de las postmodernidad comprometida de los 90 y por el cual los autores realizan una crítica a la sociedad.

\subsection{Años 90}

En la década de los 90 se han encontrado siete artículos, lo que la convierte (de forma representativa) en la década más prolija en cuanto a periodismo literario de opinión en El País. Estos artículos han sido escritos por siete autores: Manuel Vicent, Soledad Puértolas, Manuel Vázquez Montalbán, Fernando Savater, Antonio Muñoz Molina, Maruja Torres y Juan José Millás, un elenco que también representa el mayor número de autores encontrados durante una década en el análisis de este periódico. 
La estética de estos artículos sigue basándose en la superación de todo experimentalismo y en la simplicidad argumental. Es interesante observar cómo también existe una crítica hacia el descenso de los niveles estéticos de la literatura de la era postmoderna, que tiende a aligerar los textos y que estaría relacionado con la democratización cultural. Antonio Muñoz Molina (1996: 38) en su artículo Cervantes 'light', hablando justamente de esta simplificación literaria sospecha que "existe una conspiración internacional en contra de la dificultad".

Es en esta década cuando se observa más claramente cómo los elementos temáticos se ponen en relación con la descripción de la realidad identificable, un objetivo con el cual se encuentran comprometidos un gran número de escritores de los 90 . También se ha localizado el señalamiento de la importancia de la reconstrucción histórica para comprender el presente, y paradójicamente se vuelve a un cierto relativismo estético, con varios ejemplos de resistencia a catalogar la belleza en el arte.

La inclusión de elementos ideológicos va muy en la línea de los que significa esta década para el pensamiento y la literatura. A lo que más aluden los autores es a la importancia de asumir responsabilidades, lo cual representa un acto de acercamiento al lector junto al punto de vista desde el cual se construyen los artículos y las invitaciones a la reflexión mediante los apóstrofes o las preguntas retóricas. Manuel Vázquez Montalbán (1996: 80) en su artículo La pinza pide "depurar a fondo la herencia de unos aparatos de Estado formados en la cultura de la violación impune de los derechos humanos". Estos escritores también reflexionan sobre el respeto a la individualidad, tema postmoderno por excelencia.

\subsection{Años 2000}

En la década de los 2000 se han encontrado cuatro artículos redactados por cuatro escritores: Maruja Torres, Juan José Millás, Manuel Vicent y Eduardo Mendoza. Después de la década prolífica de los 90 , este es el año en el que menos artículos se han localizado en el periódico. Estos artículos han sido localizados en los periódicos del lunes, el jueves, el viernes y el domingo. Parece romperse la tendencia de incluir el periodismo literario en los primeros días de la semana, aunque en esta década no se delimita un patrón claro de localización. Se apuesta por escritores consumados que siguen realizando actualmente una labor literaria y recibiendo reconocimiento: tres de los autores han conseguido ganar el premio Nadal, y tres también el premio Planeta.

En cuanto a los elementos estéticos postmodernos, se sigue utilizando la linealidad y la simplicidad argumental con una clara y definitiva superación del experimentalismo.

Los elementos temáticos vuelven la vista hacia la descripción de un nuevo relativismo, continuando en la línea de lo analizado durante la década anterior. Lo ejemplifica claramente Eduardo Mendoza (2006: 23) en el artículo Destrozos cuando asegura que "el conocimiento y el esfuerzo están devaluados; la autoridad, bajo sospecha; no acatar las normas pasa por libertad de criterio; no aprender nada equivale a pensar 
por uno mismo". Este relativismo estaría definido por la crisis de los sistemas de referencia, la confusión entre lo real y lo virtual y la modificación de la percepción del espacio y del tiempo (nótese que estos elementos están directamente relacionados con el tremendo desarrollo de las nuevas tecnologías durante el siglo XXI). Estos elementos se juntan con la descripción de la realidad identificable, bajo un punto de vista poco comprometido con ideales políticos pero con la inclusión de algunos juicios de valor negativos.

En el análisis de los elementos ideológicos se ve cómo se pretende defender el respeto a la individualidad de las personas (un valor que según algunos autores se encuentra actualmente en crisis). En este sentido, Maruja Torres (2006: 27) en su artículo Vaticanadas arremete contra la institución de la Iglesia por considerar que se inmiscuye de forma injustificada en la vida de las personas, "se entromete en la compasión y en el derecho a sufrir lo menos posible". También se pone en relevancia el irracionalismo de la sociedad contemporánea.

\section{Conclusiones}

En los resultados recién expuestos, puede comprobarse cómo las características de las postmodernidad y el Postmodernismo literario recorren las páginas del periódico utilizado para el análisis, que puede considerarse representativo de una buena parte de la prensa española actual. Además, la naturaleza de estos artículos evoluciona al mismo ritmo que el clima cultural de nuestros últimos 40 años.

Durante la era postmoderna, un amplio abanico de escritores ha participado en la producción periodística, trasladando la naturaleza y el significado de la postmodernidad a la prensa escrita diaria. Resulta oportuno defender la entidad del periodismo literario, a partir del cual se construyen textos que seguramente cualquier lector podría identificar como artísticos de manera instintiva.

La calidad y la estética en la redacción periodística deben formar parte de un proceso de renovación del periodismo escrito que hoy necesitamos más que nunca. Atrás tiene que quedar lo esquemático, la sequedad y la despreocupación formal, elementos que seguramente sean más reflejo de nuestra sociedad que cualquier rasgo postmoderno.

\section{Bibliografía}

El País, 28-05-76

El País, 25-05-86

El País, 27-05-86

El Pais, 27-05-96 
El País, 29-05-96

El País, 25-05-06

El País, 29-05-06 